\title{
Variability and trends of rainfall, precipitation and discharges over zambezi river basin, southern africa: review
}

\begin{abstract}
Changes in temperature and rainfall have a direct effect on the quantity of evapotranspiration and on both quality and quantity of the runoff. Observed hydrological records and climate change projections indicate that freshwater resources are vulnerable to the impacts of climate change. The African continent is highly vulnerable to climate change, and the Zambezi River Basin is particularly at risk. The Zambezi River Basin has one of the most variable climates of any major river basin in the world and the runoff is highly sensitive to variations in climate, as small changes in rainfall produce large changes in runoff. Over the next century, climate change is expected to increase this variability, and the vulnerability of the basin. This paper reviewed likely changes in runoff in response to changes in air temperature and precipitation over in southern Africa (Angola, Namibia, Mozambique, Zimbabwe, Zambia, Botswana and South Africa) and Zambezi River in particular. After a review of the main conclusions of various experiments and documentations, it was concluded that the details of climate change trends and forecasts for Southern Africa can be difficult to discern from the high level of natural variability in temperature, rainfall, and runoff. Although, we observed changes in southern Africa rainfall through the last century. There is drying trend and several scholars concluded that temperatures are rising in southern Africa. Overall, the Zambezi basin is expected to experience a significant warming trend and rainfall will decrease as well as become shorter and more variable, experiencing more prolonged drought periods and more extreme floods. Furthermore, all Zambezi Basin countries will experience a significant reduction in average annual stream flow.
\end{abstract}

Keywords: Variability, Climate change, Extremes Events, Zambezi river Basin
Volume 2 Issue 2 - 2018

Felix Banze, Jiali Guo, Shi Xiaotao

College of Hydraulic and Environmental Engineering, China

Three Gorges University, Yichang 443002, China

Correspondence: Felix Banze, College of Hydraulic and Environmental Engineering, China Three Gorges University, Yichang 443002, China, Tel +861557273767,

Email felixbanze@gmail.com

Received: December 20, 2017| Published: March 12, 2018

\section{Introduction}

Human influence on the climate system is clear, and recent anthropogenic emissions of greenhouse gases are the highest in history. Their effects, together with those of other anthropogenic drivers, have been detected throughout the climate system and are extremely likely to have been the dominant cause of the observed warming since the mid-20th century. Recent climate changes have had widespread impacts on human and natural systems. Warming of the climate system is unequivocal, and since the 1950s, many of the observed changes are unprecedented over decades to millennia. ${ }^{1}$ according to Res \& Trenberth, ${ }^{2}$ there is a direct influence of global warming on precipitation. Increased heating leads to greater evaporation and thus surface drying, thereby increasing the intensity and duration of drought. The African continent has been identified as particularly vulnerable to the changing climate due to its envisaged low adaptive capacity and vulnerability and the southern African region is regarded as one of the most vulnerable regions in Africa. ${ }^{3}$ This affects the water resource in terms of quality and quantity of water. ${ }^{4}$ Africa is highly vulnerable to the impacts of climate change and numerous climate change models predict that the continent's weather patterns will become more variable, and extreme weather events are expected to be more frequent and severe, with increasing risk to health and life. ${ }^{1,4,5}$ The droughts and floods will increase in their frequency leading to more water stress. Alterations in agricultural, livestock and fisheries productivity will occur and Africa will face further food insecurity as well as possibly the spread of water-related diseases.

According to Swain et al., ${ }^{6}$ Zambezi basin is already experiencing drastic changes to its climate. In recent years the annual rainfall in the region decreased considerably and affected the annual flow levels. Over 128 million inhabitants that are part of the Zambezi River Basin are dependent on this river directly or indirectly as a source of food and water. In total the countries along the Zambezi Basin have 2.17 million $\mathrm{km}^{2}$ of agricultural land, of which just $202,900 \mathrm{~km}^{2}$ is arable. But as a consequence of increased agricultural land, there is also an increased need for irrigation. The Intergovernmental Panel on Climate Change (IPCC) has categorized the Zambezi as the river basin exhibiting the "worst" potential effects of climate change among 11 major African basins. Over the next century, climate change is expected to increase this variability, and the vulnerability of the basin and its hydropower dams. ${ }^{5}$ The Zambezi River Basin has one of the most variable climates of any major river basin in the world and the runoff is highly sensitive to variations in climate, as small changes in rainfall pattern produce large changes in runoff. The hydrology of the basin is very important for hydropower generation, water supply, Irrigation and other ecological processes. This paper aimed to review the literature on changes in runoff in response to changes in air temperature and precipitation over the southern Africa and Zambezi River in particular. 


\section{Literature review}

Within the climate change matrix, water resources are at the epicenter of projected climate change impacts. If the observed changes in climate in the last century persist into the future, the potential impacts on water resources are likely to increase in magnitude, diversity and severity (IPCC, 2007). Climate change impacts on water resources are likely to be more pronounced in the near future than previously foreseen (IPCC, 2007b). Climate change impacts on water resources will have both direct and indirect effects on intensification of the hydrological cycle, which in turn could have significant impacts on the availability (both quantity and quality) and distribution of water resources. ${ }^{7}$ While climate influences virtually all aspects of life, the impact on agricultura production is likely to be particularly important. Despite the fact that the relative importance of these impacts is still under debate, there is genera consensus that in South Africa, due to climate change, the resulting changes in regional water endowments and soil moisture will affect the productivity of cropland. A doubling of irrigation development, on the other hand, will not be sufficient to reverse adverse impacts from climate change in the country. ${ }^{8,9}$

\section{Temperature trends}

Several studies investigating temperature trends over South Africa have been published in the literature. Analyses of both remote sensing derived and observed temperature records in southern Africa agree that over the last decades the region has been experiencing a warming trend. Several studies ${ }^{10-14}$ have analyzed the observed temperature trends and the basic conclusion from their investigation is that the temperature in the region is rising, with minimum temperature rising faster than maximum temperature ${ }^{15}$ indicated that extreme daily maximum and minimum temperatures have warmed for most regions of the world including Africa since 1950. Florida, ${ }^{12}$ investigated the variation of near-surface air temperature anomalies in Africa between 1979 and 2010 and found significant increasing temperature trends in each of the following region examined: all of Africa, Northern Hemisphere Africa, Southern Hemisphere Africa, tropical Africa, and subtropical Africa. Muhlenbruch (1992) reported a decrease in maximum temperature but an increase in minimum temperatures in South Africa between 1940 and 1989. These findings were later contrasted by Karl et al. ${ }^{11}$ who reported an increase in both maximum temperatures and minimum temperatures but a decrease in the diurnal temperature range in South Africa, for the period 1951 to $1991^{10}$ analyzed 26 climate stations in South Africa and a total of 23 stations showed positive trends in their annua mean maximum temperature series, 13 of them were significant. Annual mean minimum temperatures showed 21 stations having positive trends, with 18 significant ${ }^{13}$ investigated trends in daily maximum and minimum extreme temperature indices from 28 weather stations in South Africa for the period of 1962 - 2009 and concluded that warm extremes increased and cold extremes decreased. Freddy et al. ${ }^{14}$ investigated the temperature trends over Limpopo Province, South Africa, for the period 1950 to 1999, and observed an increase of $0.12^{\circ} \mathrm{C}$ per decade in the mean annual temperature for the 30 catchments A non-uniform pattern of changes in temperature was evident across the different catchments; $13 \%$ of the catchments showed negative trends while $87 \%$ showed positive trends in their annual mean temperature. Furthermore $20 \%$ of catchments showed negative trends while $80 \%$ of catchments showed positive trends in their diurnal temperature range. Samba \& $\mathrm{Nganga}^{16}$ analyzed maximum and minimum temperatures time series of Congo-Brazzaville, where the temperatures series showed an irregular increase. Moreover, ${ }^{5}$ reported that in future the whole Zambezi River Basin is expected to become hotter, drier and more variable, experiencing more prolonged drought periods and more extreme floods. In general, we can conclude that for southern Africa associated with Zambezi River Basin, the maximum and minimum temperature is rising, with minimum temperatures rising faster than maximum temperatures for the whole region. As a result there is also a notable decrease in cold extremes and an increase in warm extremes. The daily temperature anomalies indicate that extreme daily maximum and minimum temperatures have warmed for most regions since 1950

\section{Rainfall trends}

It is recognized that rainfall is one of the key climatic variables that affect both the spatial and temporal patterns of water availability. ${ }^{17,18}$ In recent decades many studies have been done on climate trends, especially for precipitation and temperature, compared to the time before the issue of climate change which became more prominent during the 1980s. Rainfall variability and changes in Southern Africa over the 20th century and their potential links to the global warming have been discussed ${ }^{19-23}$ which indicated that rainfall variability in Southern Africa has experienced significant modifications, especially in the recent decades. Inter annual variability has increased, droughts and flood became more intense and widespread. ${ }^{20,21}$ examined spatial variations of trends of relevant extreme precipitation indices for 138 rainfall stations in South Africa for the period 1910 to 2004 and concluded that, while in the largest part of South Africa there has been no real evidence of changes in precipitation over the past century, there are however some identifiable areas where significant changes in certain characteristics of precipitation have occurred over the period 1910 to $2004 . .^{22}$ reported that currently, rainfall trends are characterized by more severe droughts in the southwest of southern Africa and enhanced rainfall farther north in Zambia, Malawi, and northern Mozambique. According to Kitoh et al., ${ }^{23}$ the heavy precipitation indices have increased in all regional domains of Southern Africa, although the mean precipitation decreased. According to Koninklijk Nederlands Meteorologisch Instituut, ${ }^{24}$ models generally show a drying trend for much of the 21 st century for Southern Africa. Hamududu ${ }^{25}$ found increases in northern Zambia and southern Congo while the northern Congo basin found reductions and in southern African region, there is a tendency of decline in precipitation. To the west, in Angola, the mainland showed increases while towards the coast some decreases in precipitation was indicated. In South Africa, Hewitson et al. $^{26}$ reported the rainfall increment in regions where orography plays a strong role, and also increases in late summer dry spell duration for much of the summer rainfall region from 1950 to 1999 . Nxumalo et al. ${ }^{27}$ observed an increase in rainfall in the southern interior of South Africa, and indicated the decrease in rainfall in the far northern and north-eastern parts. Thus, most of the country experienced increases in the intensity of daily rainfall. This study improves our knowledge compared to previous studies in the region due to doubling of the analysis period, largely eliminating the influence of the decadal-scale cycles which might have influenced analyses over shorter periods. However, some differences in the trend results compared to previous studies are apparent, e.g., less pronounced drying in the east and the previously observed increase in rainfall in the western and southern interior not extending as far as the south-western Cape. Rainfall fluctuation is characterized by high inter-annual variability in this area. There is also drying trend for much of the 21 st century for Southern Africa, The simulated annual cycles in a warmer climate show a delay of the rainfall, thus implying shorter rainy seasons. Muchuru et al. ${ }^{28}$ analyzed average monthly and annual rainfall recorded for the period 1970 to 2010 from 13 stations across the Lake Kariba catchment area of the Zambezi river basin and observed that that the annual and seasonal rainfall series were homogeneous and demonstrated no apparent significant shifts. Hydro meteorological disasters are not a new phenomenon in Zambezi river basin, several droughts and floods have afflicted the basin in recent times. For example 1986-87, 1991-95, 1997-98 and 2003-04 are some of the recent drought years, while the period 1999 to 2001 saw the basin experiencing some of the worst floods in living memory. ${ }^{29}$ These studies suggest that the annual rainfall observation has not given a clear tendency in the last century, but most concur that dry periods in southern Africa have become longer and more intense. Rainfall is characterized by high inter-annual variability over this region.

\section{Projected changes}

Climate change is having a multitude of immediate and long-term impacts on water resources in African countries. These include flooding, drought, sea-level rise in estuaries, drying up of rivers, poor water quality in surface and groundwater systems, precipitation and water vapor pattern distortions, and snow and land ice mal-distribution. These effects when compounded together have devastating impacts on ecosystems and communities, ranging from economic and social impacts to health and food insecurity, all of which threaten the continued existence of many regions in Africa. ${ }^{30}$

\section{Projected changes in temperature}

Since the second IPCC report highlighted the paucity of information on 
warming trends and variability of temperature over southern Africa, a number of studies documenting such changes have emerged. ${ }^{5,31-34}$ According to Hague,${ }^{31}$ the temperature in Africa is expected to increase by $2-5^{\circ} \mathrm{C}$. Research findings of Mujere et al. ${ }^{35}$ revealed that doubling of $\mathrm{CO}_{2}$ in 2050 would significantly increase mean monthly temperature by $3^{\circ} \mathrm{C}$. According to Li et al. ${ }^{33}$ the projected temperature shows an increasing tendency over Southern Africa in the near future until 2029. Graham et al..$^{34}$ found a $3^{\circ} \mathrm{C}$ maximum temperature increase for Thukela Catchment in South Africa. According to Hamududu et al. ${ }^{36}$ the temperature projections in the Zambezi basin indicate an increase up to $2.7^{\circ} \mathrm{C}$ by end of the century and Beilfuss, ${ }^{5}$ projected $0.3-0.6^{\circ} \mathrm{C}$ increase per decade $\left(0.8^{\circ} \mathrm{C}\right.$ in the summer months by 2050). Future climate predictions indicate that the southern Africa including Zambezi River Basin will be hotter and drier than at present. The annual temperature is expected to increase 1.5 to $3.0^{\circ} \mathrm{C}$ by 2050 compared to the $1961-1990$ average. ${ }^{37}$ For surface-air temperature, climate policy consistently reduces the modal value of warming, and this reduction is strongest for the western Zambezi River Basin. Climate policy also considerably abates the occurrence of the most extreme temperature increases, but the minimum warming in the distributions is less affected. ${ }^{32}$ Several studies indicate that there will be warming trend for temperature in southern Africa and the climate will become hotter and drier, and projections show that temperature changes will not be uniform over the region.

\section{Projected changes in precipitation}

Inter annual and inter decadal variations in precipitation have had majo implications for human livelihoods and societies across southern Africa throughout the historical period (Hannaford and Nash, 2016). Frequency distributions of precipitation change for the unconstrained emission scenario indicate a majority of the outcomes to be drier by 2050, although the distribution spans both increased and decreased precipitation (Schlosser and Strzepek 2015). The observed global warming, the human induced increase in concentrations of greenhouse gases in the atmosphere, and the development of numerical climate models, have led to an increased concern for the detection of long term changes in climate characteristics. According to Li et al..$^{33}$ the precipitation changes projected (until 2029) in southern Africa are varying between different months and sub-regions. The annual average rainfall in southern Africa (Angola, Namibia, Mozambique, Zimbabwe, Zambia, Botswana and South Africa) will decrease by $5-15 \%$ in the south and by $5-10 \%$ in the north. ${ }^{37}$ Increase in the annual rainfall of Southern Africa by 32 to $41 \mathrm{~mm}$ yr-1 per decade has been expected by Maidment et al. ${ }^{38}$ Mean rainfall and rainfall variability is under estimated (or over-estimated) over we (dry) regions of southern Africa. ${ }^{39}$ Global Circulation Model (GCM) multimodel predictions indicate a general wetting trend in the north-eastern parts of southern Africa (Tanzania, Malawi). In the far south-west (South Africa, parts of Namibia), conditions may become drier ${ }^{40}$ and reduced rainfall for much southern Africa in winter (May-July), but increased annual rainfall in the north-eastern tropical regions linked to increasing summer rainfall. Rainfall patterns are also expected to change in intensity and frequency, resulting in more extreme events and longer dry periods between rainfalls Hewitson et al. ${ }^{41}$ reported that South Africa will experience increased summer rainfall over the convective region of the central and eastern plateau and the Drakensberg Mountains. The Western Cape will see little change, with some slight drying in summer and a slight decrease in wintertime frontal rainfall. For Mazoe catchment in Zimbabwe, Mujere et al. ${ }^{35}$ reported that by doubling of $\mathrm{CO} 2$ in 2050 the mean monthly rainfall would significantly increase by $15 \%$. According to Hamududu et al. ${ }^{36}$ the simulations for air temperature and potential evaporation are projected to increase, while rainfall is projected to decrease in Zambezi River Basin. ${ }^{5}$ projected $10-25 \%$ increase in evaporation and $10-15 \%$ reduction in rainfall, relative to the baseline (1961-1990). In conclusion, the distribution of precipitation spans both increased and decreased precipitation over southern Africa with variations between different month and sub-regions and there is no consensus of magnitude of potential rainfall change over the region.

\section{Projected changes in runoff}

Surface water is fundamental for many sectors in Southern Africa, including agriculture, power generation and fisheries. River discharge is affected by several drivers such as land use changes, water withdrawals and climate variations. As underlined by the above example, variability in climate, and especially rainfall, plays a significant role in flow variation. ${ }^{42}$ According to $\mathrm{Li}$ et al. ${ }^{33}$ an increase in runoff was found in eastern part of Southern Africa, i.e. Southern Mozambique and Malawi, while a decrease was estimated across the driest region in a wide area encompassing Kalahari Desert, Namibia, southwest of South Africa and Angola. the strongest climate change signals are found over humid tropical areas, i.e. north of Angola and Malawi and south of Dem Rep of Congo; and large spatial and temporal variability of climate change signals is found in the near future over Southern Africa. Comparisons between historical and future scenarios show that the biggest changes have already occurred in Zambezi River Basin. Construction of Kariba and Cahora Bassa dams in the mid 1900 altered the seasonality and flow duration curves. Low flows have been increased and high flows decreased. Future climate causes large uncertainties in future discharge. This is caused by the high sensitivity of discharge to precipitation, but the analyzed climate models do not agree on the sign of future changes in precipitation. Low flows may be drastically reduced if analyzing scenarios with more than $10 \%$ change in future precipitation. Future warming will cause higher actual evapotranspiration and therefore lower discharge. ${ }^{43}$ The majority of the Zambezi basin will likely be drier, except for a portion in the north around Malawi and northern Zambia. Irrigation demands are likely to be unmet in Mozambique and Zimbabwe, and hydropower generation is likely to be reduced in Zambia. ${ }^{36,44}$ According to the simulations, air temperature and potential evaporation are projected to increase, while rainfall is projected to decrease, which together contribute to a decrease in river flows. Consequently, the decrease in water resources will lead to decreased hydropower production potential, by $9 \%$ in 2020 s, $18 \%$ in 2050 s and $28 \%$ in 2080 s in the hydropower system, using A1B emission scenario.

\section{Conclusion}

The details of climate change trends and forecasts for Southern Africa can be difficult to discern from the high level of natural variability in temperature, rainfall, and runoff; and confounded by the relatively low density of longterm monitoring stations across the continent. A few Regional Climate Models (RCMs) downscaled from global models recently have been constructed for Africa ${ }^{40}$ but further modeling efforts (now underway) are needed to improve the accuracy of climate forecasts specific to the Zambezi Basin and its subbasins. River basin managers often site this "uncertainty" as a justification for ignoring or downplaying climate change. ${ }^{45}$

\section{Acknowledgments}

The authors greatly would like to thank the China Scholarship Council (CSC) for supporting this research by providing funds for the ongoing $\mathrm{PhD}$ research. The authors would further like to thank the anonymous reviewers and editor for comments and suggestions on the manuscript.

\section{Conflict of interest}

The authors declare no conflict of interest.

\section{References}

1. IPCC. Core Writing Team, RK Pachauri and L.A. Meyer Climate Change 2014: Synthesis Report. Contribution of Working Groups I, II and III to the Fifth Assessment Report of the Intergovernmental Panel on Climate Change. 2014a

2. Res, Clim, Kevin ET. Changes in Precipitation with Climate Change. Climate research. 2011;47(1-2):123-38.

3. IPCC. Summary for Policymakers. Climate Change 2014: Impacts, Adaptation and Vulnerability - Contributions of the Working Group II to the Fifth Assessment Report. 2014b:1-32.

4. Solomon S, Qin D, Manning M, et al. The Physical Science Basis Contribution of working group I to the fourth assessment report of the intergovernmental panel on climate change. 2007:235-337.

5. Beilfuss, Richard. A Risky Climate for Southern African Hydro: Assessing Hydrological Risks And Consequences For Zambezi River Basin Dams. International Rivers (September). 2012;1-5. 
6. Swain, Ashok, Ranjula BS, et al. A Risk Zone of Climate Change and Economic Vulnerability. New Routes 3. 2012:17-20.

7. Kankam Y, Kwabena, et al. Impact of Climate Change on Streamflow in Selected River Basins in Ghana Impact of Climate Change on Streamflow in Selected River Basins in Ghana. Tandfonline. 2016a;58(4):773-788

8. Calzadilla, Alvaro, Tingju Z, et al. Climate Change and Agriculture : Impacts and Adaptation Options in South Africa. Water Resources and Economics. 2014;5:24-48

9. Blignaut, James, Liza U, et al. Agriculture Production's Sensitivity to Changes in Climate in South Africa. South African Journal of Science. 2009: 1-13.

10. Kruger AC, Shongwe S. Temperature Trends In South Africa: 1960 - 2003. Int J climat. 2004;24(15):1929-45.

11. Karl, Thomas R, Richard W, et al. Asymmetric Trends of Daily Maximum and Minimum Temperature. Natural resources. 1993:119.

12. Jennifer MC. Temperature Variability over Africa. AMS. 2011:364966.

13. Kruger AC, Sekele SS. Trends in Extreme Temperature Indices in South Africa: 1962-2009. Int J climat. 2013;33(3):661-76.

14. Freddy, Milambo, Tshiala C, et al. Analysis of Temperature Trends over Limpopo Province, South Africa. Journal of geography and geology. 2011;3(1):13-21.

15. Brown SJ, Caesar J, Ferro CAT. Global Changes in Extreme Daily Temperature Since 1950. Atmospheres. 2008;113:1-11.

16. Samba, Gaston, Dominique N. Minimum and Maximum Temperature Trends in Congo-Brazzaville: 1932-2010. Sci res. 2014(3): 404-30.

17. Ravento J, Luis MD, Cortina J, et al. Spatial Analysis Of Rainfal Trends In The Region Of Valencia (east Spain). Int J Clim. 2000;20(11):1451-69.

18. Kampata JM, Parida BP, Moalafhi DB. Trend Analysis of Rainfall in the Headstreams of the Zambezi River Basin in Zambia. Physics and Chemistry of the Earth. 2008;33(8-13):621-25.

19. Reason CJC. ENSO-Like Decadal Variability and South African Rainfall. Geophysical research letters. 2000;29(13):13-16.

20. Fauchereau N, Trzaska S, Rouault M, et al. Rainfall Variability and Changes in Southern Africa During the 20th Century in the Global Warming Context. Natural hazards. 2003;29(2):139-154.

21. Kruger AC. Observed Trends In Daily Precipitation Indices In South Africa: 1910 - 2004. Int J climat. 2006;26(15):2275-85.

22. Shongwe M, Van OG, Van Den HB. Projected Changes in Mean and Extreme Precipitation in Africa Under Global Warming. Part I Southern Africa. AMS. 2009:3819-37.

23. Kitoh, Akio, Hirokazu E. Changes in Precipitation Extremes Projected by a $20-\mathrm{Km}$ Mesh Global Atmospheric Model. Weather and Climate Extremes. 2016;11:41-52.

24. KNMI. Changes in Extreme Weather in Africa Under Globa Warming. Koninklijk Nederland's Meteorologisch Instit. 2000:1-8.

25. Hamududu, Byman H. Impacts of Climate Change on Water Resources and Hydropower Systems in Central and Southern Africa. Skipnes. 2012.

26. Hewitson BC, Crane RG. Consensus Between Gcm Climate Change Projections With Empirical Downscaling: Precipitation Downscaling Over South Africa. Int J climat. 2006;26(10):1315-37.
27. Nxumalo M, Kruger A. Historical Rainfall Trends in South Africa: 1921 - 2015. Water SA. 2017;43(2):285-97.

28. Muchuru S, Joel JB, Willem AL, et al. Variability of Rainfall over Lake Kariba Catchment Area in the Zambezi River Basin, Zimbabwe. Theoretical and Applied Climatology. 2015;124(1-2):325-338.

29. Chagutah, Tigere. Recent Floods in the Zambezi Basin - a Result of Climate Change?. Managing water resources. 2006;6(3):1-8.

30. Urama, Kevin C, Nicholas O. Impacts Of Climate Change On Water Resources In Africa: the Role of Adaptation. Climate Adaptation. 2010: 1-29.

31. Hague T. Projected Changes in Mean and Extreme Precipitation in Africa Under Global Warming. Part II : East Africa. AMS 2011:3718-33.

32. Schlosser, Adam C, Kenneth S. Regional Climate Change of the Greater Zambezi River Basin: a Hybrid Assessment. Springer. 2015;130(1):9-19

33. Li Lu, Ismaïla D, Chong-yu X, et al. Hydrological Projections Under Climate Change in the Near Future by RegCM4 in Southern Africa Using a Large-Scale Hydrological Model. Journal of Hydrology. 2015;528:1-16.

34. Graham, Phil L, et al. Using Multiple Climate Projections for Assessing Hydrological Response to Climate Change in the Thukela River Basin, South Africa. Physics and Chemistry of the Earth 2011;36(14-15):727-35.

35. Mujere N, Mazvimavi D. Impact of Climate Change on Reservoir Reliability. African crop science Journal. 2012;20:545-51.

36. Hamududu, Byman H, Ånund K. Hydropower Production in Future Climate Scenarios; the Case for the Zambezi River. Energies. 2016;9(7):1-18.

37. Ragab, Christel P. Climate Change and Water Resources Managemen in Arid and Semi-Arid Regions: Prospective and Challenges for the 21st Century. Biosystems Eng. 2012;81(1):3-34.

38. Maidment RI, Richard PA, Emily B. Recent observed and simulated changes in Precipitation over Africa. Geophysical research letters. 2015;8155-64

39. Williams CJR, Kniveton DR, Layberry R. Assessment of a Climate Model to Reproduce Rainfall Variability and Extremes over Southern Africa. Theoretical and Applied Climatology. 2009;99(1-2):9-27.

40. Christensen JH, Hewitson B, Busuioc A, et al. Rainfall Variability and Changes in Southern Africa During the 20th Century in the Global Warming Context. 2007.

41. Hewitson BC, Crane RG. Gridded Area-Averaged Daily Precipitation via Conditional Interpolation. AMS. 2006:41-57.

42. Roudier P, Ducharne A, Feyen L. Climate Change Impacts on Runoff in West Africa: a Review. Hydrol Earth Syst sci. 2014:2789-2801.

43. Kling, Harald, Philipp S, et al. Impact Modelling of Water Resources Development and Climate Scenarios on Zambezi River Discharge. Journal of Hydrology: Regional Studies. 2014;1:17-43.

44. Fant, Charles, Yohannes G, et al. An Uncertainty Approach to Assessment of Climate Change Impacts on the Zambezi River Basin. Climate change. 2015;130(1):35-48.

45. ACPC. Climate Change and Water Resources of Africa: Challenges, Opportunities and Impacts. United Nations Economic Commission for Africa African Climate Policy Centre. 2011. p. 1-33. 